\title{
Magnetic Anisotropy in Single Crystals: A Review
}

\author{
Andrea R. Biedermann (i) \\ Institute of Geophysics, Department of Earth Sciences, ETH Zurich, Sonneggstrasse 5, 8092 Zürich, Switzerland; \\ andrea.regina.biedermann@gmail.com
}

Received: 20 July 2018; Accepted: 9 August 2018; Published: 11 August 2018

\begin{abstract}
Empirical relationships between magnetic fabrics and deformation have long served as a fast and efficient way to interpret rock textures. Understanding the single crystal magnetic properties of all minerals that contribute to the magnetic anisotropy of a rock, allows for more reliable and quantitative texture interpretation. Integrating information of single crystal properties with a determination whether or not mineral and magnetic fabrics are parallel may yield additional information about the texture type. Models based on textures and single crystal anisotropies help assess how the individual minerals in a rock contribute to the rock's anisotropy, and how the individual anisotropy contributions interfere with each other. For this, accurate and reliable single crystal data need to be available. This review paper discusses magnetic anisotropy in single crystals of the most common rock-forming minerals, silicates and carbonates, in relation to their mineralogy and chemical composition. The most important ferromagnetic minerals and their anisotropy are also discussed. This compilation and summary will hopefully lead to a deeper understanding of the sources of magnetic anisotropy in rocks, and improve the interpretation of magnetic fabrics in future structural and tectonic studies.
\end{abstract}

Keywords: magnetic anisotropy; magnetic fabric; AMS; single crystals; olivine; pyroxene; amphibole; mica; feldspar; carbonate

\section{Introduction}

The preferred alignment of minerals in a rock can provide important information in geodynamic, structural and tectonic studies, e.g., to investigate transport or deformation processes. A fast and efficient way of characterizing this alignment is based on magnetic fabrics, e.g., anisotropy of magnetic susceptibility (AMS) or anisotropy of magnetic remanence (AMR), which are commonly used as proxies for rock textures [1-7]. Compared to direct texture-determining techniques such as U-stage and X-ray texture goniometry or electron backscatter diffraction, magnetic methods have the advantage that they provide a time-efficient integrated measure of the mineral alignment over a large volume and can capture several mineral types and a wide range of grain sizes. Because magnetic data acquisition and processing are fast, the number of samples that can be analyzed increases significantly compared to direct texture-determining techniques, thus allowing to characterize both small-scale and regional variations within a single study.

Traditionally, magnetic fabrics have been interpreted based on empirical relationships. For example, AMS has been shown to reflect the macroscopic foliation and lineation in many rocks, i.e., the maximum susceptibility $\left(k_{1}\right)$ indicates lineation, and the minimum susceptibility $\left(k_{3}\right)$ is normal to foliation [8-16]. However, the magnetic and mineral fabrics are not always parallel. In amphibolites, for example, $k_{1}$ can be deviated from the macroscopic lineation by up to $90^{\circ}$, even though both magnetic and mineral fabrics are defined by hornblende [17-19]. A second empirical relationship that is often used is that the degree of magnetic anisotropy increases linearly with strain $[9,13,20-28]$. The details of this relationship have to be established for each rock type separately, because it also depends on 
mineralogy [29,30]. For example, AMS-strain relationships exhibit different slopes in different regions of the Alpes Maritimes [21]. This observation is related to the fact that the degree of anisotropy intrinsic to the carrier mineral defines the upper limit of anisotropy that can be observed in a rock in the extreme case of perfect mineral alignment. Hence, observed anisotropy is controlled by both the degree of mineral alignment, as well as intrinsic mineral anisotropy, and mineralogy plays an important role in defining magnetic fabrics.

In the meantime, magnetic fabrics have been linked to crystallographic preferred orientation of rock-forming minerals such as phyllosilicates [9,31-35], or shape preferred orientation and distribution of magnetite [36-39]. Furthermore, quantitative models have been developed to predict anisotropy based on the mineral alignment $[19,40-44]$. The accuracy of calculating anisotropy based on crystallographic preferred orientation largely relies on well-defined single crystal properties as input parameters.

Single crystal magnetic anisotropy has been investigated since the 1850s [45], and attracted increased interest once the importance of mineralogy, and hence each mineral's intrinsic properties, became evident in magnetic fabric studies. Early studies carefully linked magnetic anisotropy to crystallographic directions, often measuring spherical samples (thus avoiding any influence of shape anisotropy) on instruments similar to today's torquemeters [45-53]. Many of these early studies focused on magnetic anisotropy in diamagnetic crystals, correcting for the susceptibility of the air surrounding the sample [47]. The same method was used to determine the anisotropy of organic molecules [54-56]. With the advent of low-field AMS methods, large datasets of single crystal properties could be generated [57-60]. However, this method has the disadvantage that it measures a superposition of both dia/paramagnetic contributions to the anisotropy (crystal itself), and the ferromagnetic anisotropy related to iron oxide exsolutions within the crystal. Therefore, high-field methods are preferred again in the most recent single crystal studies [61-64]

Because of their abundance, and their importance in defining fabrics, the magnetic anisotropy of phyllosilicates has been studied extensively. Numerous studies report that the minimum susceptibility of phyllosilicates is normal to their basal plane (001) [57,61,65-70]. These studies also show that the degree of anisotropy depends on mineralogy, i.e., biotite has a higher anisotropy than chlorite and muscovite. Further, it was demonstrated that the anisotropy of biotite increases more strongly with decreasing temperature than for other phyllosilicates [69,70]. Other minerals, e.g., olivine, amphiboles and pyroxenes, have been investigated, but yielded inconsistent results with regard to principal anisotropy directions, degree and shape of anisotropy [51,58-60,62,63,71-78]. Lagroix and Borradaile [60] attributed these inconsistencies to the presence of oriented ferromagnetic inclusions within the crystals. Even single crystals may contain iron oxides, which have a preferred orientation because they exsolved parallel to distinct crystallographic directions or planes [79-81]. These exsolutions can contribute to, or completely dominate the crystal's low-field anisotropy $[62,63,73]$. To overcome this problem, techniques have been developed to separate the ferromagnetic contribution to anisotropy (inclusions) from the para- and diamagnetic components carried by the crystal itself, or to enhance the paramagnetic contribution [82-87]. Based on these techniques, it has been possible to characterize the isolated magnetocrystalline anisotropy of many common rock-forming minerals, which then relates to the crystal structure, chemical composition, and the oxidation state of iron $[62-64,70,73,88]$.

In contrast to dia/paramagnetic minerals that possess solely magnetocrystalline anisotropy, ferromagnetic minerals (sensu lato) may possess shape anisotropy in addition [89]. In fact, shape and distribution anisotropy dominate in magnetite $[37,38,90]$. For pyrrhotite, both shape and magnetocrystalline anisotropy have been described, and anisotropy is field-dependent [91,92]. Hematite possesses magnetocrystalline anisotropy that is also field-dependent [93-95]. Note that although a small amount of ferromagnetic minerals may dominate the mean susceptibility of a crystal or rock, it does not necessarily dominate their anisotropy $[7,30,32,96-99]$. 
A solid understanding of the magnetic anisotropy of single crystals is an essential prerequisite for interpreting magnetic fabrics quantitatively. In particular when magnetic fabrics are used to infer mineral alignment, it is important to know how the magnetic anisotropy in a crystal is related to the crystal lattice and the composition of the crystal. This review paper discusses single crystal magnetic anisotropy for rock-forming minerals in the silicate and carbonate group, and also summarizes data on accessory minerals that are important in magnetic studies, i.e., iron oxides and sulfides.

\section{Theory}

\subsection{Diamagnetic, Paramagnetic, and Ferromagnetic Anisotropy}

Even what we call single crystals may consist of several anisotropy carriers, e.g., the silicate host and oxide exsolutions. A careful characterization of the magnetic anisotropy tensor will therefore separate out the diamagnetic, paramagnetic and ferromagnetic contributions to AMS. These individual contributions as well as different sub-populations of ferromagnetic grains can be separated based on a variety of methods, e.g., temperature-dependence, high-field methods, anisotropy of full or partial remanence, or by comparing in-phase and out-of-phase susceptibility $[85,100,101]$.

Diamagnetic susceptibility is a property of all materials, and related to the orbital moments of the electrons. Diamagnetic anisotropy arises when the electron orbits cover different areas in different directions. For example, in pure calcite, the most negative susceptibility is parallel to [001], because the electron clouds of the $\mathrm{CO}_{3}{ }^{2-}$ groups are aligned in the (001) plane [64]. Diamagnetic susceptibility and anisotropy are independent of field and temperature.

Paramagnetic susceptibility is associated with partially filled electron orbitals, and is particularly strong when many orbitals are only partially filled. In minerals, it is mainly Fe (and $\mathrm{Mn}, \ldots$ ) that causes paramagnetic susceptibility. Therefore, paramagnetic anisotropy is related to the site occupancy, distribution, concentration, and oxidation state of Fe. For example, the Fe in distorted octahedral sites in phyllosilicates and amphiboles causes a minimum susceptibility normal to the octahedral planes or bands $[62,65,67,70]$. Paramagnetic susceptibility and anisotropy are independent of field, but susceptibility increases with decreasing temperature according to the Curie-Weiss law.

Ferromagnetic susceptibility and anisotropy are caused when the magnetic moments of strongly magnetic ions (e.g., Fe) interact with each other. They are observed in e.g., iron oxides and iron sulfides. Ferromagnetic susceptibility and its anisotropy are independent of temperature in a first-order approximation. They can show field-dependence in low fields, and saturate in high fields.

\subsection{Description of Magnetic Fabrics}

Magnetic fabrics in minerals and rocks are generally represented by symmetric second-order tensors. Tensors can be determined for the diamagnetic, paramagnetic and ferromagnetic components of the anisotropy, or the superposition of all contributions. The eigenvalues, $k_{1} \geq k_{2} \geq k_{3}$, and eigenvectors of each tensor, referred to as principal susceptibilities and principal susceptibility directions, define the magnitude ellipsoid of the respective contribution [102]. Note that the susceptibility of some minerals can contain higher-order components; for example, a threefold symmetry has been described in the basal planes of some hematite and pyrrhotite crystals $[92,93,103]$. These higher-order components are not reflected by second-order tensors, but they can be analyzed, e.g., by torque magnetometry.

Susceptibility can be measured as full or deviatoric tensor. For full tensors, the average of the eigenvalues defines the mean susceptibility, $\frac{\left(k_{1}+k_{2}+k_{3}\right)}{3}=k_{\text {mean }}$. Therefore, they are often presented in their normalized form, with $\left(k_{1}+k_{2}+k_{3}\right)=3$. Deviatoric tensors describe the deviation from mean susceptibility, so that $k_{i}$ of the deviatoric tensor equals $k_{i}-k_{\text {mean }}$ of the corresponding full tensor, and for the deviatoric tensor $k_{1}+k_{2}+k_{3}=0$. Many parameters have been defined to describe the degree and shape of anisotropy [3,104]. Only few of them are universally applicable to both full and deviatoric tensors. A selection of these will be used throughout this review paper: anisotropy degree 
will be described by $k^{\prime}=\sqrt{\left(\left(k_{1}-k_{\text {mean }}\right)^{2}+\left(k_{2}-k_{\text {mean }}\right)^{2}+\left(k_{3}-k_{\text {mean }}\right)^{2}\right) / 3}$ [105], and anisotropy shape by $U=\left(2 * k_{2}-k_{1}-k_{3}\right) /\left(k_{1}-k_{3}\right)$.

\subsection{Symmetry Constraints}

Neumann's principle $[106,107]$ states that any physical property of a crystal must include all the symmetry elements of the crystal itself. In other words, tensorial properties must have equal or higher symmetry than the crystal lattice. This poses important constraints on the allowed eigenvector orientations for second-order tensors, and may require that several eigenvalues be equal, especially for high-symmetry minerals. For example, for cubic minerals $k_{1}=k_{2}=k_{3}$ and the susceptibility is isotropic. Hexagonal, tetragonal and trigonal minerals have $k_{1}=k_{2}$ or $k_{2}=k_{3}$, and the unique axis $\left(k_{3}\right.$ or $k_{1}$ ) must be aligned with the crystallographic [001] axis. The eigenvalues can differ for orthorhombic crystals $\left(k_{1} \geq k_{2} \geq k_{3}\right)$, but each eigenvector has to be aligned with a crystallographic axis. Monoclinic crystals must have one eigenvector parallel to the [010] axis. There are no symmetry constraints on triclinic crystals.

Whether or not Neumann's principle is fulfilled can give a first estimate on the data quality when measuring single crystal magnetic anisotropy. Similarly, Neumann's principle can help evaluate whether previously reported anisotropy tensors are accurate. When symmetry constraints are violated, this may indicate that a superposition of several components of anisotropy was measured, the data is affected by noise, or the crystal may have been misoriented.

\section{Measurement Methods}

Because susceptibility is represented by a symmetric second-order tensor, at least 6 independent measurements are needed to describe it. More measurements will allow for assessing data quality, and defining confidence intervals for both the eigenvalues, and the directions of the eigenvectors. Common measurements schemes determine (1) directional susceptibilities for a predefined set of orientations, or (2) susceptibility differences in three mutually perpendicular planes. These methods in general yield full and deviatoric tensors, respectively, but the latter can be integrated with at least one directional susceptibility measurement to calculate the full tensor. Measuring deviatoric tensors is more accurate than measuring full tensors [102,108].

The distinct field- and temperature-dependencies of ferromagnetic, paramagnetic and diamagnetic susceptibilities can be used in order to enhance certain contributions, or separate the individual components of the anisotropy. For example, measuring samples at liquid nitrogen temperature $(77 \mathrm{~K})$ instead of room temperature enhances the paramagnetic contribution to the anisotropy. High-field measurements, conducted on a torquemeter or vibrating sample magnetometer, allow for separating the ferromagnetic from the para/diamagnetic anisotropy components. High-field torque measurements in combination with different temperatures allow for full separation of the ferromagnetic from the paramagnetic from the diamagnetic sub-fabrics [82-87,109]. Additionally, several methods have been developed to assess the anisotropy of remanence carriers $[101,110,111]$.

\section{Single Crystal Properties of Silicate Minerals}

The most common rock-forming minerals belong to the silicate group. Depending on their structure, defined by the bonding between different $\mathrm{SiO}_{4}{ }^{4-}$ tetrahedra, silicates are categorized as phyllosilicates (sheets), nesosilicates (isolated), inosilicates (single and double chains), cyclosilicates (circles) and tectosilicatets (3D framework). The magnetocrystalline anisotropy of minerals from these silicate groups will be described in this chapter.

\subsection{Phyllosilicates: Mica and Chlorite}

The main characteristic of phyllosilicates are their tetrahedral sheets, $\mathrm{Si}_{2} \mathrm{O}_{5}{ }^{2-}$. Within these sheets, each $\mathrm{SiO}_{4}{ }^{4-}$ is linked to three neighbors with its three basal oxygen atoms. They are stacked with 
octahedral sheets and interlayer cations, and different stacking sequences define the mica, chlorite, or clay minerals. Most of these minerals are flaky, with a prominent cleavage parallel to the sheets, which makes them good tectonic markers. Magnetic anisotropy has been characterized for micas and chlorite (Figure 1a). The iron atoms are located within the octahedral sheets [112,113]. Small distortions of these octahedral sites lead to an easy-plane anisotropy with the unique axis normal to the plane of the sheets, the so-called basal plane, (001) [65]. This leads to a minimum susceptibility $k_{3}$ normal to the basal plane in biotite, phlogopite, muscovite and chlorite. If there is any anisotropy within the basal plane, it is negligible. Therefore, principal susceptibility directions are usually reported with respect to the orientation of the sheets, without determining the exact orientation of [100] and [010] [57,61,65-70]. The observed magnetic anisotropy has a higher symmetry than the monoclinic crystal lattice, which is in accordance with Neumann's principle.

The degree of anisotropy is higher in biotite than other sheet silicates. It also shows the strongest temperature dependence in biotite [69]. These observations were explained with varying Fe contents, and the fact that at $77 \mathrm{~K}$, the Fe atoms interact within the basal planes of biotite, but not between them. For the other phyllosilicate minerals, the Fe concentration is too small for interactions to occur [70]. The increase in anisotropy degree at $77 \mathrm{~K}$ compared to room temperature, $p_{77}^{\prime}=\frac{k{ }_{77} \mathrm{~K}}{\mathrm{k}{ }_{R T}}$, is 11.1 to 12.2 for biotite, and 6.6 to 8.7 for muscovite, chlorite, and phlogopite [70].

\subsection{Nesosilicates: Olivine, Chloritoid}

Isolated $\mathrm{SiO}_{4}{ }^{4-}$ tetrahedra bonded by interstitial cations define the nesosilicates. Iron is present as interstitial cation [114]. Nesosilicates whose magnetic anisotropy has been characterized, include olivine and chloritoid.

Chloritoid occurs in Al-rich metapelitic rocks. Although chloritoid is a nesosilicate, its structure resembles that of sheet silicates, because the isolated tetrahedra are arranged in layers, with octahedral layers in-between. Similar to phyllosilicates, the minimum susceptibility is normal to the layers, and the anisotropy within this basal plane is negligible (Figure 1b) [115]. Chloritoid possesses monoclinic crystal symmetry, and the anisotropy has higher symmetry, consistent with Neumann's principle. At this time, no statement can be made about the relationship between iron concentration and anisotropy parameters, because chemical compositions have not been reported.

Olivine makes up large parts of the Earth's mantle. Its magnetic anisotropy has been studied repeatedly; however, conflicting results have been reported [71-74,78,116,117]: The maximum susceptibility $k_{1}$ has been attributed to the crystallographic [100] or [001] axes, $k_{2}$ to [100], [010], or [001], and $k_{3}$ to [100], [010], or [001]. Note that all of these options are consistent with the symmetry requirements of olivine's orthorhombic crystal system. Most studies agree that $k_{1}$ is parallel to [001] [71,73,74,78,116], and Biedermann, Pettke, Reusser and Hirt [73] have shown that the orientation of $k_{2}$ and $k_{3}$ at room temperature depends on the Fe content (Figure 1c). The minimum susceptibility aligns with [100] for 3-5 wt.\% FeO, and with [010] for 6-10 wt.\% FeO. The latter orientation was also observed in weathered olivine with 16 to $18 \mathrm{wt} \%$ FeO. At $77 \mathrm{~K}, k_{3}$ is parallel to [010], independent of iron content, and $k_{1}$ is parallel to [001] except for the weathered olivine, where it aligns with [100]. The degree of anisotropy increases with Fe content both at room temperature and at $77 \mathrm{~K}$, and the shape changes from highly prolate to less prolate or oblate. At $77 \mathrm{~K}$, the anisotropy degree is 6.0 to 8.4 times stronger than at room temperature $\left(p^{\prime}{ }_{77}\right)$.

\subsection{Inosilicates: Pyroxenes and Amphiboles}

Inosilicates consist of either single chains (pyroxenes, $\mathrm{Si}_{2} \mathrm{O}_{6}{ }^{4-}$ ) or double chains (amphiboles, $\mathrm{Si}_{8} \mathrm{O}_{22}{ }^{12-}$ ) of $\mathrm{SiO}_{4}{ }^{4-}$ tetrahedra. In pyroxenes, cations can occupy the M1 sites located in the octahedral chains in-between the tetrahedral chains, or the M2 sites which have an irregular six- to eightfold coordination. In amphiboles, the octahedral bands contain three sites, M1, M2 and M3, which are characterized by variable distortions of the octahedra. Polyhedral M4 sites have at least a six-fold 
coordination, and A sites are coordinated by 12 oxygens. Depending on the size of the cations in their M2 or M4 sites, respectively, pyroxenes and amphiboles are either monoclinic or orthorhombic [118,119].

(a) Phyllosilicates: Biotite, Phlogopite, Muscovite, Chlorite

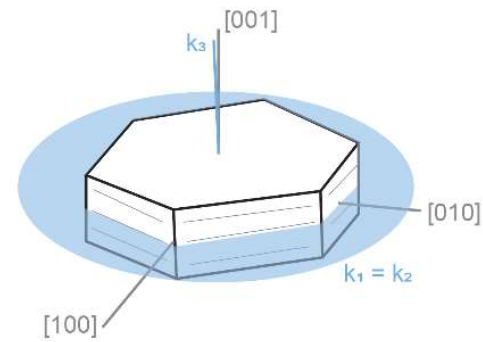

(b) Nesosilicates: Chloritoid

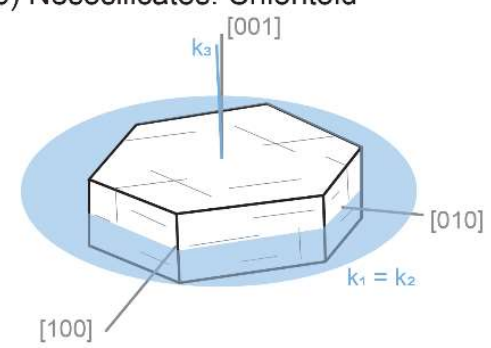

(c) Nesosilicates: Olivine

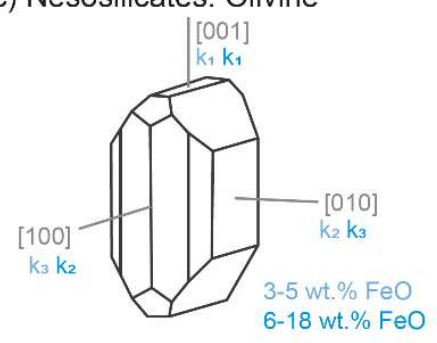

(d) Inosilicates: Clinopyroxene
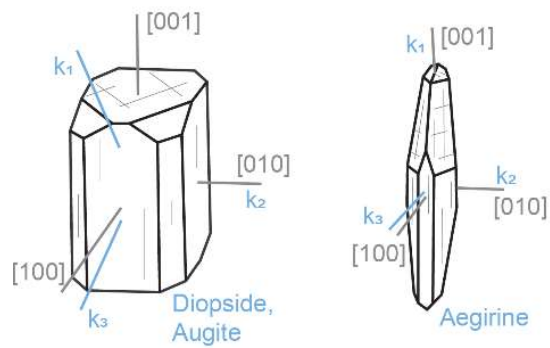

(e) Inosilicates: Orthopyroxene

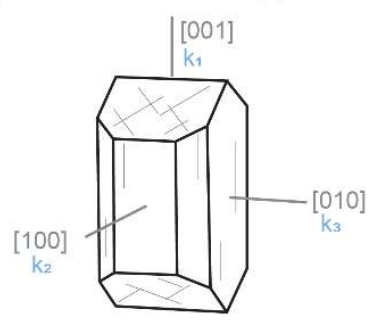

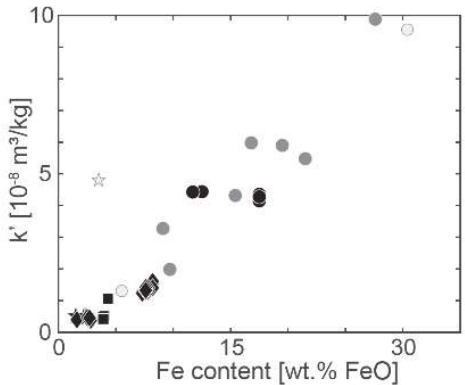

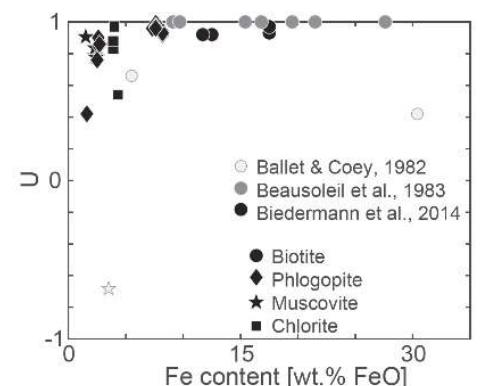

No chemical data available
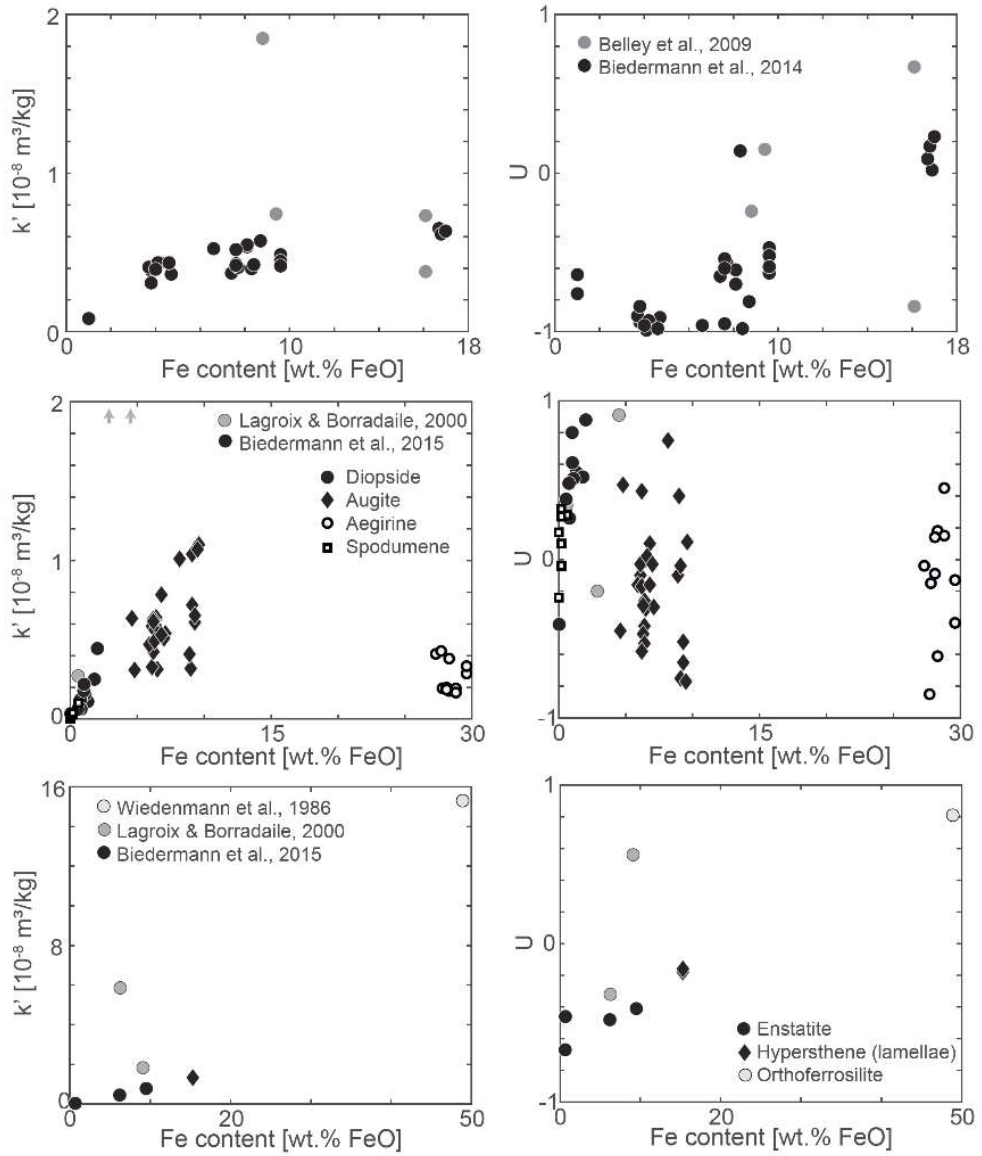

Figure 1. Cont. 
(f) Inosilicates: Amphiboles

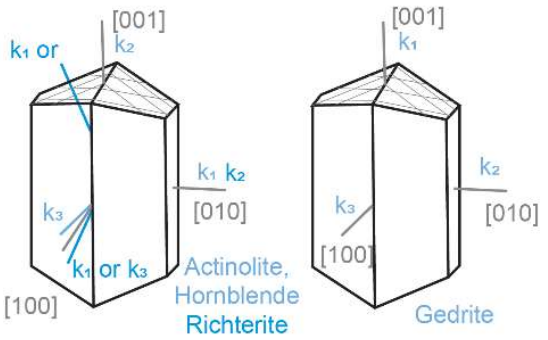

(g) Tectosilicates: Quartz

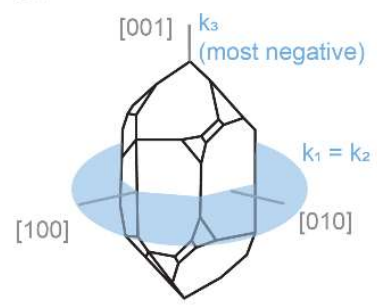

(h) Tectosilicates: Feldspar

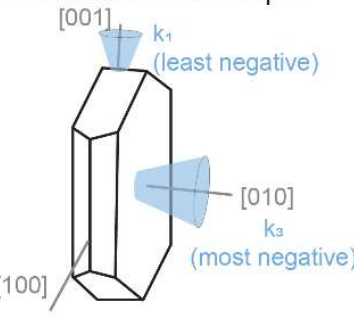

(i) Carbonates (trigonal)

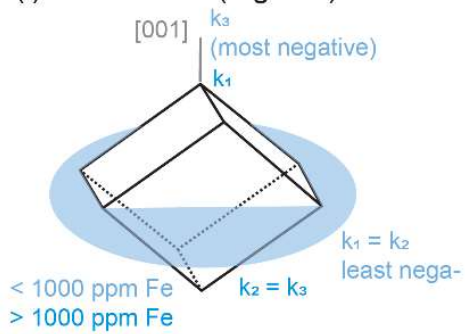

(j) Magnetite

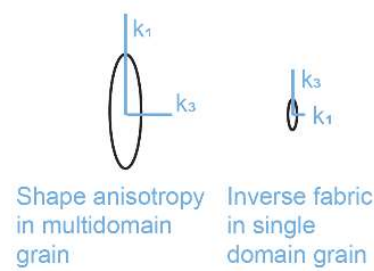

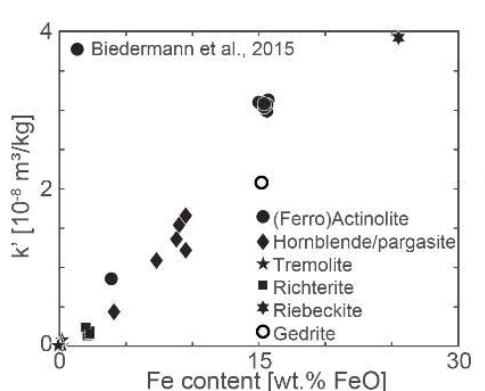

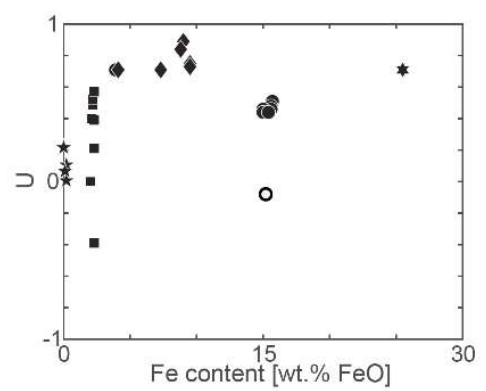

No chemical data available
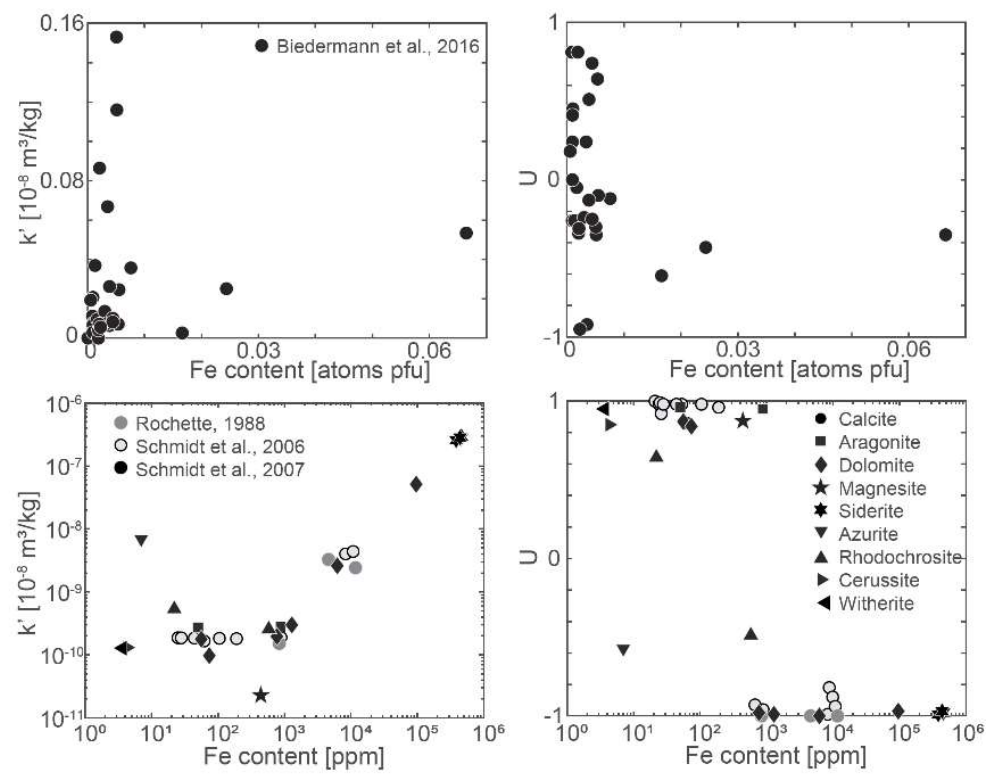

(k) Hematite, pyrrhotite

(I) Hemo-ilmenite
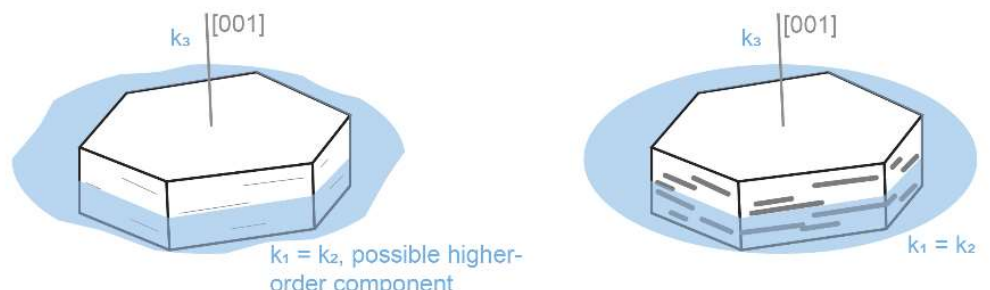

Figure 1. Principal directions, degree $\left(k^{\prime}\right)$ and shape of anisotropy $(U)$ as a function of Fe content for silicates, carbonates and some ferromagnetic minerals.

In clinopyroxenes, $\mathrm{Fe}^{2+}$ is mainly located in $\mathrm{M} 1$ sites, whereas in orthopyroxenes, it prefers the M2 sites. $\mathrm{Fe}^{3+}$ is found in the M1 sites for both clino- and orthopyroxenes. The different site occupancy of $\mathrm{Fe}^{2+}$ leads to distinct magnetic anisotropies. Most clinopyroxenes have their $k_{2}$ aligned with [010], and $k_{1}$ and $k_{3}$ are in the [100]-[001]-plane (Figure 1d) [63,75]. Note that some crystals have one principal susceptibility axis close to, but not parallel to [010] [60]. This is not allowed by crystal symmetry 
constraints, and highlights the importance of separating subfabrics. In diopside and augite, $k_{1}$ is at a $45^{\circ}$ angle to [001]. On the contrary, in aegirine, $k_{1}$ is parallel to [001], $k_{2}$ parallel to [010], and $k_{3}$ parallel to (100). Aegirine contains mainly $\mathrm{Na}$ and $\mathrm{Fe}^{3+}$ rather than $\mathrm{Ca}$ and $\mathrm{Fe}^{2+}$, which explains its different magnetic anisotropy. No consistent behavior was observed in spodumene, possibly due to the weak susceptibility and anisotropy of these crystals [63]. The degree of anisotropy generally increases with iron content, and is additionally affected by the $\mathrm{Fe}^{2+} / \mathrm{Fe}^{3+}$ ratio. Namely, aegirine has a lower degree of anisotropy than augite, because $\mathrm{Fe}^{2+}$ contributes to anisotropy, but $\mathrm{Fe}^{3+}$ is expected to be isotropic based on their electron structure [63]. The values for $p^{\prime}{ }_{77}$ cover the range from 2.7 to 20.8, where the extremes on both ends are likely due to unseparated diamagnetic components, or a low signal-to-noise-ratio.

Due to their higher symmetry, orthopyroxenes need to have each of their principal susceptibilities parallel to a crystallographic axis, which again illustrates that subfabrics need to be separated [60]. The maximum susceptibility has been reported parallel to [010] [76], or [001] [60,63], and $k_{3}$ parallel to [100] [76] or [010] [63] (Figure 1e). This seeming inconsistency may be related to different iron contents. The degree of anisotropy increases with iron content, and $U$ appears to change from prolate to oblate. $p^{\prime}{ }_{77}$ varies between 7.3 and 8.6.

In amphiboles, iron can occupy the octahedral M1-M3 sites (clinoamphiboles), or the M4 site (orthoamphiboles). Whether $\mathrm{Fe}^{2+}$ prefers the M1, M2, or M3 sites, depends on the exact composition of each amphibole. The smaller $\mathrm{Fe}^{3+}$ is preferentially located in M2. These differences again result in distinct magnetic anisotropies for different minerals of the amphibole group. Initial studies on amphibole anisotropy reported maximum susceptibilities either close to [001] or [010], and minimum susceptibilities parallel to [100] or [010] [51,59,60,75]. In the meantime, amphibole magnetic tensors have been determined in relation to mineral group: $k_{1}$ is parallel to [010], and $k_{3}$ normal to (100) for actinolite, ferroactinolite, pargasite, and hornblende. In richterite, $k_{2}$ is parallel to [010], and $k_{1}$ and $k_{3}$ lie in the [100]-[001]-plane (Figure 1f). Note that both sets of directions are consistent with monoclinic crystal symmetry. Results for tremolite are inconsistent due to a low signal-to-noise-ratio. Gedrite, the only orthoamphibole that has been characterized, displays $k_{1}$ parallel to [001], $k_{2}$ parallel to [010], and $k_{3}$ parallel to [100] (Figure 1f) [62]. The degree of anisotropy generally increases with Fe content. Additionally, the degree of anisotropy is slightly higher for (ferro)actinolite compared to the other amphiboles, which may be related to different site preference of $\mathrm{Fe}^{2+}$, or oxidation state [62]. $p^{\prime}{ }_{77}$ covers the range from 5.3 to 13.4 .

\subsection{Tectosilicates: Quartz and Feldspar}

Tectosilicates are made up of infinite three-dimensional frameworks of $\mathrm{SiO}_{4}{ }^{4-}$ tetrahedra, where each oxygen is shared by two tetrahedra. The most important tectosilicates in rocks are quartz and feldspar. In its ideal composition, quartz contains only Si and O. In feldspar, Si is partially replaced by $\mathrm{Al}$, and cations are incorporated into the holes of the framework in order to maintain charge balance. Despite their abundance, only few studies discuss the magnetic anisotropy of quartz or feldspar [47,50-52,120,121], because they are weakly magnetic, and their contribution to anisotropy is outweighed by small amounts of iron-bearing mafic minerals [121].

The few data available for quartz agree that the most negative susceptibility is aligned with [001], and susceptibility is isotropic in the (001) plane (Figure 1g). This is in accordance with the trigonal symmetry of quartz.

Feldspars can have positive or negative susceptibility, depending on how much their real composition deviates from the ideal formula. Interestingly, even in crystals with positive mean susceptibility, the magnetic anisotropy is dominated by a diamagnetic component with the maximum (or least negative) susceptibility close to [001], and minimum (or most negative) sub-parallel to [010] (Figure 1h). This is related to a preferred plane for electrons along the bases of the $\mathrm{SiO}_{4} \mathrm{Or}^{\mathrm{AlO}_{4}}$ tetrahedra in the (010) plane [121]. Because feldspars can be monoclinic or triclinic, symmetry may require that one principal susceptibility is parallel to [010], or there may be no symmetry constraints. 
Hence, these results are consistent with Neumann's principle. No clear relationships were observed between iron content and anisotropy parameters, likely because iron is not always present in the crystal structure, but rather in a variety of inclusions and/or exsolutions.

\section{Single Crystal Properties of Carbonate Minerals}

Carbonates are the second common group of rock-forming minerals. Similar to feldspars, many carbonate minerals can display a diamagnetic or paramagnetic mean susceptibility, depending on their exact composition. Two categories of anisotropy tensors have been described for carbonates: (1) crystals with low iron content (< 1000 ppm) have their minimum (most negative) susceptibility parallel to the [001] axis, and a highly oblate anisotropy shape; (2) in crystals with higher iron contents, $k_{1}$ is aligned with [001], and the crystals possess highly prolate anisotropy (Figure 1i) [6,50,53,64,88,120,122-124]. Most carbonate minerals (calcite, dolomite, magnesite, siderite, rhodochrosite) have trigonal symmetry, which requires that the unique axis of any second-order tensor property is parallel to [001], and that the property is isotropic within the (001) plane. Some carbonates (aragonite, cerussite, witherite) have orthorhombic symmetry, and azurite is monoclinic. Hence, the principal directions and anisotropy shapes of these minerals are not as strictly constrained. The relationship between degree of anisotropy and Fe content is not straightforward; at low Fe contents, anisotropy decreases with $\mathrm{Fe}$, then increases linearly with Fe once the Fe concentration reaches $>1000$ ppm $[64,88,124]$. This relationship is a direct consequence of a composite anisotropy made up of two subfabrics: (1) a diamagnetic component related to preferred planes of electron movement within (001) with its most negative susceptibility parallel [001], and (2) a paramagnetic anisotropy carried by $\mathrm{Fe}^{2+}$ cations in the crystal structure, with $k_{1}$ along [001]. Anisotropy is high when one contribution dominates, and low when they have similar strength so that they cancel each other $[64,88]$.

\section{Ferromagnetic Minerals}

Ferromagnetic minerals are present as primary or secondary accessory minerals in many rocks, and in some places, they form ore bodies. In rocks, the ferromagnetic minerals occur as individual grains, as unoriented inclusions, and/or as oriented exsolutions within the host silicates. Magnetic fabrics in ores are defined by the shape or crystallographic preferred orientation and distribution of ferromagnetic grains. Of particular interest in fabric studies is when the ferromagnetic accessory grains record different stages of deformation than the bulk rock, or when several sub-populations of ferromagnetic grains record different deformation stages.

Whereas magnetite does possess a weak magnetocrystalline anisotropy, it mainly contributes to anisotropy in rocks through shape and distribution anisotropy [36-39]. Because of self-demagnetization caused by the strong magnetization in magnetite, sufficiently large grains of magnetite will have their $k_{1}$ parallel to the grain elongation, and $k_{3}$ parallel to the shortest direction of the grain (Figure 1j). Note that single domain magnetite particles display inverse fabrics with $k_{3}$ parallel to the long grain axis, along which they are already magnetized [125]. The susceptibility and anisotropy of pure magnetite are field-independent, but the susceptibility and anisotropy of titanomagnetite display a field-dependence [126,127].

Magnetocrystalline anisotropy has been described in both hematite, hemo-ilmenite, and pyrrhotite (Figure 1k,l) [14,91-94,103,128-131]. These minerals display a magnetocrystalline anisotropy with $k_{3}$ normal to the basal plane, i.e., parallel to (001). Some hematite and pyrrhotite crystals show additional higher-order contributions to anisotropy within the basal plane $[103,131]$. Furthermore, shape effects have been observed in pyrrhotite [91]. Note that the anisotropy of hematite and pyrrhotite is field-dependent [93-95,132].

\section{Application of Single Crystal Magnetic Anisotropy to Fabric Interpretation}

Even based solely on empirical relationships between principal susceptibility directions or anisotropy degree and strain, magnetic fabrics have been a powerful tool in investigating tectonic and 
geodynamic processes [1,2,4]. Today, carefully characterized single crystal susceptibility anisotropies, in combination with methods to average tensor properties [43,133], allow for a deeper and quantitative understanding of magnetic fabrics. For example, it is now possible to model individual mineral's contributions to anisotropy, and to investigate how they interfere with each other $[19,34,35,40,42]$. These models can help interpret complex fabrics carried by multiple components. Additionally, based on a thorough understanding of single crystal properties, we can now explain why the magnetic fabrics in most rocks are parallel to macroscopic fabrics, and why this is not always true. Some amphibolites, for example, display a maximum susceptibility direction parallel to macroscopic lineation, whereas in other amphibolites it is deviated up to $90^{\circ}$. Previously described as anomalous fabric [17], this observation is now understood as arising from the interplay of the amphibole single crystal anisotropy with texture types, i.e., the grouping of each crystallographic axis with respect to the grouping of other axes [19]. Predicting magnetic anisotropy based on single crystal properties and either simplified model textures or the measured texture of a rock will facilitate the interpretation of magnetic fabrics in future tectonic and structural studies.

\section{Conclusions and Outlook}

Magnetocrystalline anisotropy is directly linked to the properties of the crystal lattice, e.g., the structure of the electron cloud (for diamagnetic crystals), or the site occupancy, arrangement, and oxidation state of $\mathrm{Fe}$ (for paramagnetic and ferromagnetic crystals). Note that some single crystals contain ferromagnetic inclusions, and their contribution to anisotropy needs to be removed in order to describe the susceptibility of the silicate or carbonate alone. Single crystal magnetic anisotropy is constrained by crystal symmetry, because all tensorial properties need to comply with the symmetry of the crystal itself. Therefore, each mineral group has a distinct magnetic anisotropy. In addition, the orientation of principal directions, and the degree and shape of anisotropy generally vary with Fe content. Ferromagnetic minerals may possess shape anisotropy in addition to magnetocrystalline anisotropy, and their anisotropy can contain higher-order components, and be field-dependent.

The AMS is linked to the crystal structure and symmetry, Fe concentration, site occupancy, and oxidation state. While these properties may vary between geological settings, the susceptibility anisotropy per se directly reflects these crystal properties, and therefore does not depend on e.g., locality. Thus, the relationship between crystal orientation and AMS is universal. Magnetic fabrics in rocks, in turn, are directly related to the crystallographic preferred orientation of its constituent minerals. This relationship holds whether or not the magnetic fabric in a rock complies with empirical AMS-strain relationships. Thus, knowing single crystal anisotropies allows establishing a universally applicable, quantitative relationship between AMS and crystallographic preferred orientation, which will lead to more solid and reliable interpretations, and thus greatly benefit future applications of magnetic fabric in studies of e.g., deformation or transport processes.

Funding: This research was supported by the Swiss National Science Foundation, project 167609.

Acknowledgments: I am grateful to Volkmar Schmidt and Ann Hirt for introducing me to the fascinating world of magnetic anisotropy in crystals.

Conflicts of Interest: The author declares no conflict of interest.

\section{References}

1. Borradaile, G.J.; Henry, B. Tectonic applications of magnetic susceptibility and its anisotropy. Earth Sci. Rev. 1997, 42, 49-93. [CrossRef]

2. Borradaile, G.J.; Jackson, M. Structural geology, petrofabrics and magnetic fabrics (AMS, AARM, AIRM). J. Struct. Geol. 2010, 32, 1519-1551. [CrossRef]

3. Hrouda, F. Magnetic anisotropy of rocks and its application in geology and geophysics. Geophys. Surv. 1982, 5, 37-82. [CrossRef] 
4. Martín-Hernández, F.; Lüneburg, C.M.; Aubourg, C.; Jackson, M. Magnetic Fabrics: Methods and Applications; The Geological Society: London, UK, 2004; Volume 238.

5. Tarling, D.H.; Hrouda, F. The Magnetic Anisotropy of Rocks; Chapman and Hall: London, UK, 1993.

6. Owens, W.H.; Bamford, D. Magnetic, seismic, and other anisotropic properties of rock fabrics. Philos. Trans. R. Soc. A 1976, 283, 55-68. [CrossRef]

7. Rochette, P.; Jackson, M.; Aubourg, C. Rock magnetism and the interpretation of anisotropy of magnetic susceptibility. Rev. Geophys. 1992, 30, 209-226. [CrossRef]

8. Balsley, J.R.; Buddington, A.F. Magnetic susceptibility anisotropy and fabric of some adirondack granites and orthogneisses. Am. J. Sci. 1960, 258, 6-20.

9. Lüneburg, C.M.; Lampert, S.A.; Lebit, H.D.; Hirt, A.M.; Casey, M.; Lowrie, W. Magnetic anisotropy, rock fabrics and finite strain in deformed sediments of SW Sardinia (Italy). Tectonophysics 1999, 307, 51-74. [CrossRef]

10. Oliva-Urcia, B.; Rahl, J.M.; Schleicher, A.M.; Pares, J.M. Correlation between the anisotropy of the magnetic susceptibility, strain and X-ray texture goniometry in phyllites from crete, greece. Tectonophysics 2010, 486, 120-131. [CrossRef]

11. Rathore, J.S. Magnetic susceptibility anisotropy in the cambrian slate belt of north wales and correlation with strain. Tectonophysics 1979, 53, 83-97. [CrossRef]

12. Richter, C.; Ratschbacher, L.; Frisch, W. Magnetic fabrics, crystallographic preferred orientation, and strain of progressively metamorphosed pelites in the Helvetic Zone of the Central Alps (Quartenschiefer Formation). J. Geophys. Res. Solid Earth 1993, 98, 9557-9570. [CrossRef]

13. Borradaile, G.J. Magnetic susceptibility, petrofabrics and strain. Tectonophysics 1988, 156, 1-20. [CrossRef]

14. Hargraves, R.B. Magnetic anisotropy and remanent magnetism in hemo-ilmenite from ore deposits at Allard Lake, Quebec. J. Geophys. Res. 1959, 64, 1565-1578. [CrossRef]

15. Graham, J.W. Magnetic susceptibility anisotropy, an unexploited petrofabric element. Geol. Soc. Am. Bull. 1954, 65, 1257-1258.

16. Graham, J.W. Significance of magnetic anisotropy in appalachian sedimentary rocks. In The Earth Beneath the Continents: A Volume of Geophysical Studies in Honor of Merle A. Tuve; Steinhart, J.S., Smith, T.J., Eds.; American Geophysical Union: Washington, DC, USA, 1966; Volume 10, pp. 627-648.

17. Borradaile, G.J.; Stewart, R.A.; Werner, T. Archean uplift of a subprovince boundary in the canadian shield, revealed by magnetic fabrics. Tectonophysics 1993, 227, 1-15. [CrossRef]

18. Biedermann, A.R. Magnetic Properties of the Møre-Trøndelag Fault Complex. Master's Thesis, ETH Zurich, Zurich, Switzerland, 2010.

19. Biedermann, A.R.; Kunze, K.; Hirt, A.M. Interpreting magnetic fabrics in amphibole-bearing rocks. Tectonophysics 2018, 722, 566-576. [CrossRef]

20. Kligfield, R.; Lowrie, W.; Dalziel, W.D. Magnetic susceptibility anisotropy as a strain indicator in the Sudbury Basin, Ontario. Tectonophysics 1977, 40, 287-308. [CrossRef]

21. Kligfield, R.; Owens, W.H.; Lowrie, W. Magnetic susceptibility anisotropy, strain, and progressive deformation in Permian sediments from the Maritime Alps (France). Earth Planet. Sci. Lett. 1981, 55, 181-189. [CrossRef]

22. Hirt, A.M.; Lowrie, W.; Clendenen, W.S.; Kligfield, R. The correlation of magnetic anisotropy with strain in the Chelmsford Formation of the Sudbury Basin, Ontario. Tectonophysics 1988, 145, 177-189. [CrossRef]

23. Hirt, A.M.; Lowrie, W.; Clendenen, W.S.; Kligfield, R. Correlation of strain and the anisotropy of magnetic susceptibility in the Onaping Formation: Evidence for a near-circular origin of the Sudbury basin. Tectonophysics 1993, 225, 231-254. [CrossRef]

24. Borradaile, G.J. Correlation of strain with anisotropy of magnetic susceptibility (AMS). Pure Appl. Geophys. 1991, 135, 15-29. [CrossRef]

25. Cogné, J.P.; Perroud, H. Anisotropy of magnetic susceptibility as a strain gauge in the Flamanville granite, NW France. Phys. Earth Planet. Inter. 1988, 51, 264-270. [CrossRef]

26. Hrouda, F. Theoretical models of magnetic anisotropy to strain relationship revisited. Phys. Earth Planet. Inter. 1993, 77, 237-249. [CrossRef]

27. Kneen, S.J. The relationship between the magnetic and strain fabrics of some haematite-bearing slates. Earth Planet. Sci. Lett. 1976, 31, 413-416. [CrossRef] 
28. Wood, D.S.; Oertel, G.; Singh, J.; Bennett, H.F. Strain and anisotropy in rocks. Philos. Trans. R. Soc. A 1976, 283, 27-42. [CrossRef]

29. Housen, B.A.; van der Pluijm, B.A. Chlorite control of correlations between strain and anisotropy of magnetic susceptibility. Phys. Earth Planet. Inter. 1990, 61, 315-323. [CrossRef]

30. Borradaile, G. Anisotropy of magnetic susceptibility: Rock composition versus strain. Tectonophysics 1987, 138, 327-329. [CrossRef]

31. Chadima, M.; Hansen, A.; Hirt, A.M.; Hrouda, F.; Siemens, H. Phyllosilicate preferred orientation as a control of magnetic fabric: Evidence from neutron texture goniometry and low and high-field magnetic anisotropy (SE Rhenohercynian Zone of Bohemian Massif). In Magnetic Fabric: Methods and Applications; Martín-Hernández, F., Lüneburg, C.M., Aubourg, C., Jackson, M., Eds.; The Geological Society: London, UK, 2004; Volume 238, pp. 361-380.

32. Hirt, A.M.; Evans, K.F.; Engelder, T. Correlation between magnetic anisotropy and fabric for Devonian shales on the Appalachian Plateau. Tectonophysics 1995, 247, 121-132. [CrossRef]

33. Hrouda, F.; Schulmann, K.; Suppes, M.; Ullemeyer, K.; de Wall, H.; Weber, K. Quantitative relationship between low-field AMS and phyllosilicate fabric: A review. Phys. Chem. Earth 1997, 22, 153-156. [CrossRef]

34. Siegesmund, S.; Ullemeyer, K.; Dahms, M. Control of magnetic rock fabrics by mica preferred orientation-A quantitative approach. J. Struct. Geol. 1995, 17, 1601-1613. [CrossRef]

35. Schmidt, V.; Hirt, A.M.; Leiss, B.; Burlini, L.; Walter, J.M. Quantitative correlation of texture and magnetic anisotropy of compacted calcite-muscovite aggregates. J. Struct. Geol. 2009, 31, 1062-1073. [CrossRef]

36. Grégoire, V.; De Saint-Blanquat, M.; Nédélec, A.; Bouchez, J.-L. Shape anisotropy versus magnetic interactions of magnetite grains: Experiments and application to AMS in granitic rocks. Geophys. Res. Lett. 1995, 22, 2765-2768. [CrossRef]

37. Grégoire, V.; Darrozes, P.; Gaillot, P.; Nédélec, A. Magnetite grain shape fabric and distribution anisotropy vs rock magnetic fabric: A three-dimensional case study. J. Struct. Geol. 1998, 20, 937-944. [CrossRef]

38. Hargraves, R.B.; Johnson, D.; Chan, C.Y. Distribution anisotropy: The cause of ams in igneous rocks? Geophys. Res. Lett. 1991, 18, 2193-2196. [CrossRef]

39. Stephenson, A. Distribution anisotropy: Two simple models for magnetic lineation and foliation. Phys. Earth Planet. Inter. 1994, 82, 49-53. [CrossRef]

40. Martín-Hernández, F.; Kunze, K.; Julivert, M.; Hirt, A.M. Mathematical simulations of anisotropy of magnetic susceptibility on composite fabrics. J. Geophys. Res. 2005, 110, B06102. [CrossRef]

41. Owens, W.H. Mathematical model studies on factors affecting the magnetic anisotropy of deformed rocks. Tectonophysics 1974, 24, 115-131. [CrossRef]

42. Biedermann, A.R.; Kunze, K.; Zappone, A.S.; Hirt, A.M. Origin of magnetic fabric in ultramafic rocks. IOP Conf. Ser.: Mater. Sci. Eng. 2015, 82, 012098. [CrossRef]

43. Mainprice, D.; Hielscher, R.; Schaeben, H. Calculating anisotropic physical properties from texture data using the MTEX open-source package. Geol. Soc. Lond. Spec. Publ. 2011, 360, 175-192. [CrossRef]

44. Hrouda, F. Modelling relationship between bulk susceptibility and AMS in rocks consisting of two magnetic fractions represented by ferromagnetic and paramagnetic minerals-Implications for understanding magnetic fabrics in deformed rocks. J. Geol. Soc. India 2010, 75, 254-266. [CrossRef]

45. Tyndall, J. Ueber diamagnetismus und magnekrystallinische wirkung. Ann. Phys. 1851, 159, $384-416$. [CrossRef]

46. Stenger, F. Ueber das verhalten des kalkspaths im homogenen magnetischen felde. Ann. Phys. 1883, 256, 304-326. [CrossRef]

47. König, W. Magnetische untersuchungen an krystallen. Ann. Phys. 1887, 267, 273-302. [CrossRef]

48. Stenger, F. Ueber die gesetze des krystallmagnetismus. Ann. Phys. 1888, 271, 331-353. [CrossRef]

49. Tyndall, J. Researches on Diamagnetism and Magne-Crystallic Action: Including the Question of Diamagnetic Polarity; Longmans, Green \& Co.: London, UK, 1888; 288p.

50. Voigt, W.; Kinoshita, S. Bestimmung absoluter werte von magnetisierungszahlen insbesondere für kristalle. Ann. Phys. 1907, 24, 492-514. [CrossRef]

51. Finke, W. Magnetische Messungen an Platinmetallen und monoklinen Kristallen, insbesondere der Eisen-, Kobalt-und Nickelsalze. Ann. Phys. 1909, 336, 149-168. [CrossRef]

52. Krishnan, K.S.; Guha, B.C.; Banerjee, S. Investigations on magne-crystallic action. Part I: Diamagnetics. Philos. Trans. R. Soc. A 1933, 231, 235-262. [CrossRef] 
53. Rowland, H.A. On the diamagnetic constants of bismuth and calc-spar in absolute measure. Am. J. Sci. 1879, 18, 360-371. [CrossRef]

54. Pauling, L. The diamagnetic anisotropy of aromatic molecules. J. Chem. Phys. 1936, 4, 673-677. [CrossRef]

55. Banerjee, S. The magnetic anisotropies of some organic crystals in relation to their structures. Z. Krist. 1939, 100, 316-355. [CrossRef]

56. Krishnan, K.S.; Ganguli, N. Temperature variation of the magnetic anisotropy of graphite. Z. Krist. 1939, 100, 530-536. [CrossRef]

57. Zapletal, K. Low-field susceptibility anisotropy of some biotite crystals. Phys. Earth Planet. Inter. 1990, 63, 85-97. [CrossRef]

58. Borradaile, G.; Keeler, W.; Alford, C.; Sarvas, P. Anisotropy of magnetic susceptibility of some metamorphic minerals. Phys. Earth Planet. Inter. 1987, 48, 161-166. [CrossRef]

59. Wagner, J.-J.; Hedley, I.G.; Steen, D.; Tinkler, C.; Vuagnat, M. Magnetic anisotropy and fabric of some progressively deformed ophiolitic gabbros. J. Geophys. Res. 1981, 86, 307-315. [CrossRef]

60. Lagroix, F.; Borradaile, G.J. Magnetic fabric interpretation complicated by inclusions in mafic silicates. Tectonophysics 2000, 325, 207-225. [CrossRef]

61. Martín-Hernández, F.; Hirt, A.M. The anisotropy of magnetic susceptibility in biotite, muscovite and chlorite single crystals. Tectonophysics 2003, 367, 13-28. [CrossRef]

62. Biedermann, A.R.; Bender Koch, C.; Pettke, T.; Hirt, A.M. Magnetic anisotropy in natural amphibole crystals. Am. Mineral. 2015, 100, 1940-1951. [CrossRef]

63. Biedermann, A.R.; Pettke, T.; Bender Koch, C.; Hirt, A.M. Magnetic anisotropy in clinopyroxene and orthopyroxene single crystals. J. Geophys. Res. Solid Earth 2015, 120, 1431-1451. [CrossRef]

64. Schmidt, V.; Günther, D.; Hirt, A.M. Magnetic anisotropy of calcite at room-temperature. Tectonophysics 2006, 418, 63-73. [CrossRef]

65. Ballet, O.; Coey, J.M.D. Magnetic properties of sheet silicates; 2:1 layer minerals. Phys. Chem. Miner. 1982, 8 , 218-229. [CrossRef]

66. Coey, J.M.D.; Ballet, O.; Moukarika, A.; Soubeyroux, J.L. Magnetic properties of sheet silicates; 1:1 layer minerals. Phys. Chem. Miner. 1981, 7, 141-148. [CrossRef]

67. Beausoleil, N.; Lavallee, P.; Yelon, A.; Ballet, O.; Coey, J.M.D. Magnetic properties of biotite micas. J. Appl. Phys. 1983, 54, 906-915. [CrossRef]

68. Ballet, O.; Coey, J.M.D.; Burke, K.J. Magnetic properties of sheet silicates; 2:1:1 layer minerals. Phys. Chem. Miner. 1985, 12, 370-378. [CrossRef]

69. Pares, J.M.; van der Pluijm, B.A. Phyllosilicate fabric characterization by low-temperature anisotropy of magnetic susceptibility (LT-AMS). Geophys. Res. Lett. 2002, 29, 68:1-68:4. [CrossRef]

70. Biedermann, A.R.; Bender Koch, C.; Lorenz, W.E.A.; Hirt, A.M. Low-temperature magnetic anisotropy in micas and chlorite. Tectonophysics 2014, 629, 63-74. [CrossRef]

71. Müller, R.; Fuess, H.; Brown, P.J. Magnetic properties of synthetic fayalite $\left(\alpha-\mathrm{FE}_{2} \mathrm{SiO}_{4}\right)$. J. Phys. Colloq. 1982, 43, 249-252. [CrossRef]

72. Belley, F.; Ferré, E.C.; Martín-Hernández, F.; Jackson, M.J.; Dyar, M.D.; Catlos, E.J. The magnetic properties of natural and synthetic $\left(\mathrm{Fe}_{\mathrm{x}}, \mathrm{Mg}_{1-\mathrm{x}}\right)_{2} \mathrm{SiO}_{4}$ olivines. Earth Planet. Sci. Lett. 2009, 284, 516-526. [CrossRef]

73. Biedermann, A.R.; Pettke, T.; Reusser, E.; Hirt, A.M. Anisotropy of magnetic susceptibility in natural olivine single crystals. Geochem. Geophys. Geosyst. 2014, 15, 3051-3065. [CrossRef]

74. Ferré, E.C.; Tikoff, B.; Jackson, M. The magnetic anisotropy of mantle peridotites: Example from the Twin Sisters Dunite, Washington. Tectonophysics 2005, 398, 141-166. [CrossRef]

75. Parry, G.R. The Magnetic anisotropy of some deformed rocks. Ph.D. Thesis, University of Birmingham, Birmingham, UK, 1971.

76. Wiedenmann, A.; Regnard, J.-R.; Fillion, G.; Hafner, S.S. Magnetic properties and magnetic ordering of the orthopyroxenes $\mathrm{Fe}_{x} \mathrm{Mg}_{1-\mathrm{x}} \mathrm{SiO}_{3}$. J. Phys. C Solid State Phys. 1986, 19, 3683-3695. [CrossRef]

77. Ballet, O.; Fuess, H.; Wacker, K.; Untersteller, E.; Treutmann, W.; Hellner, E.; Hosoya, S. Magnetisation measurements of the synthetic olivine single crystals $\mathrm{A}_{2} \mathrm{SiO}_{4}$ with $\mathrm{A}=\mathrm{Mn}$, Fe or Co. J. Phys. Condens. Matter 1989, 1, 4955-4970. [CrossRef]

78. Ehrenberg, H.; Fuess, H. Analytical interpretation and simulation of the static magnetic properties of synthetic alpha- $\mathrm{Fe}_{2} \mathrm{SiO}_{4}$. J. Phys. Condens. Matter 1993, 5, 3663-3672. [CrossRef] 
79. Feinberg, J.M.; Wenk, H.-R.; Renne, P.R.; Scott, G.R. Epitaxial relationships of clinopyroxene-hosted magnetite determined using electron backscatter diffraction (EBSD) technique. Am. Mineral. 2004, 89, 462-466. [CrossRef]

80. Feinberg, J.M.; Scott, G.R.; Renne, P.R.; Wenk, H.-R. Exsolved magnetite inclusions in silicates: Features determining their remanence behavior. Geology 2005, 33, 513-516. [CrossRef]

81. Feinberg, J.M.; Harrison, R.J.; Kasama, T.; Dunin-Borkowski, R.E.; Scott, G.R.; Renne, P.R. Effects of internal mineral structures on the magnetic remanence of silicate-hosted titanomagnetite inclusions: An electron holography study. J. Geophys. Res. 2006, 111, B12S15. [CrossRef]

82. Martín-Hernández, F.; Hirt, A.M. Separation of ferrimagnetic and paramagnetic anisotropies using a high-field torsion magnetometer. Tectonophysics 2001, 337, 209-221. [CrossRef]

83. Ferré, E.C.; Martin-Hernandez, F.; Teyssier, C.; Jackson, M. Paramagnetic and ferromagnetic anisotropy of magnetic susceptibility in migmatites: Measurements in high and low fields and kinematic implications. Geophys. J. Int. 2004, 157, 1119-1129. [CrossRef]

84. Martín-Hernández, F.; Hirt, A.M. A method for the separation of paramagnetic, ferrimagnetic and haematite magnetic subfabrics using high-field torque magnetometry. Geophys. J. Int. 2004, 157, 117-127. [CrossRef]

85. Martín-Hernández, F.; Ferré, E.C. Separation of paramagnetic and ferrimagnetic anisotropies: A review. J. Geophys. Res. Solid Earth 2007, 112. [CrossRef]

86. Kelso, P.R.; Tikoff, B.; Jackson, M.; Sun, W. A new method for the separation of paramagnetic and ferromagnetic susceptibility anisotropy using low field and high field methods. Geophys. J. Int. 2002, 151, 345-359. [CrossRef]

87. Richter, C.; van der Pluijm, B.A. Separation of paramagnetic and ferrimagnetic susceptibilities using low-temperature magnetic susceptibilities and comparison with high-field methods. Phys. Earth Planet. Inter. 1994, 82, 113-123. [CrossRef]

88. Schmidt, V.; Hirt, A.M.; Hametner, K.; Gunther, D. Magnetic anisotropy of carbonate minerals at room temperature and 77 k. Am. Mineral. 2007, 92, 1673-1684. [CrossRef]

89. Uyeda, S.; Fuller, M.D.; Belshe, C.; Girdler, R.W. Anisotropy of magnetic susceptibility of rocks and minerals. J. Geophys. Res. 1963, 68, 279-291. [CrossRef]

90. Cañón-Tapia, E. Factors affecting the relative importance of shape and distribution anisotropy in rocks: Theory and experiments. Tectonophysics 2001, 340, 117-131. [CrossRef]

91. De Wall, H.; Worm, H.-U. Field dependence of magnetic anisotropy in pyrrhotite: Effects of texture and grain shape. Phys. Earth Planet. Inter. 1993, 76, 137-149. [CrossRef]

92. Martin-Hernandez, F.; Dekkers, M.J.; Bominaar-Silkens, I.M.A.; Maan, J.C. Magnetic anisotropy behaviour of pyrrhotite as determined by low- and high-field experiments. Geophys. J. Int. 2008, 174, 42-54. [CrossRef]

93. Martin-Hernandez, F.; Guerrero-Suarez, S. Magnetic anisotropy of hematite natural crystals: High field experiments. Int. J. Earth Sci. 2012, 101, 637-647. [CrossRef]

94. Guerrero-Suarez, S.; Martin-Hernandez, F. Magnetic anisotropy of hematite natural crystals: Increasing low-field strength experiments. Int. J. Earth Sci. 2012, 101, 625-636. [CrossRef]

95. Hrouda, F. Low-field variation of magnetic susceptibility and its effect on the anisotropy of magnetic susceptibility of rocks. Geophys. J. Int. 2002, 150, 715-723. [CrossRef]

96. Borradaile, G.; Mothersill, J.; Tarling, D.; Alford, C. Sources of magnetic susceptibility in a slate. Earth Planet. Sci. Lett. 1986, 76, 336-340. [CrossRef]

97. Hounslow, M.W. Magnetic fabric arising from paramagnetic phyllosilicate minerals in mudrocks. J. Geol. Soc. 1985, 142, 995-1006. [CrossRef]

98. Rochette, P. Magnetic susceptibility of the rock matrix related to magnetic fabric studies. J. Struct. Geol. 1987, 9, 1015-1020. [CrossRef]

99. Rochette, P.; Vialon, P. Development of planar and linear fabrics in Dauphinois shales and slates (French Alps) studied by magnetic anisotropy and its mineralogical control. J. Struct. Geol. 1984, 6, 33-38. [CrossRef]

100. Hrouda, F.; Chadima, M.; Jezek, J.; Pokorny, J. Anisotropy of out-of-phase magnetic susceptibility of rocks as a tool for direct determination of magnetic subfabrics of some minerals: An introductory study. Geophys. J. Int. 2016, 208, 385-402. [CrossRef]

101. Jackson, M.; Tauxe, L. Anisotropy of magnetic susceptibility and remanence: Developments in the characterization of tectonic, sedimentary, and igneous fabric. Rev. Geophys. 1991, 29, 371-376. [CrossRef] 
102. Jelinek, V. The Statistical Theory of Measuring Anisotropy of Magnetic Susceptibility of Rocks and Its Application; Geofyzika: Brno, Czech Republic, 1977.

103. Flanders, P.J.; Remeika, J.P. Magnetic properties of hematite single crystals. Philos. Mag. 1965, 11, 1271-1288. [CrossRef]

104. Jelinek, V. Characterization of the magnetic fabric of rocks. Tectonophysics 1981, 79, T63-T67. [CrossRef]

105. Jelinek, V. On a mixed quadratic invariant of the magnetic susceptibility tensor. J. Geophys. 1984, 56, 58-60.

106. Neumann, F.E. Vorlesungen über die Theorie der Elastizität der Festen Körper und des Lichtäthers; B.G. Teubner Verlag: Leipzig, Germany, 1885.

107. Nye, J.F. Physical Properties of Crystals: Their Representation by Tensors and Matrices; Clarendon Press: Oxford, UK, 1957; 322p.

108. Jelinek, V. Measuring Anisotropy of Magnetic Susceptibility on a Slowly Spinning Specimen—Basic Theory; AGICO Print No. 10; AGICO: Brno, Czech Republic, 1996.

109. Schmidt, V.; Hirt, A.M.; Rosselli, P.; Martín-Hernández, F. Separation of diamagnetic and paramagnetic anisotropy by high-field, low-temperature torque measurements. Geophys. J. Int. 2007, 168, 40-47. [CrossRef]

110. Jackson, M.J. Anisotropy of magnetic remanence: A brief review of mineralogical sources, physical origins, and geological applications, and comparison with susceptibility anisotropy. Pure Appl. Geophys. 1991, 136, 1-28. [CrossRef]

111. Potter, D.K. A comparison of anisotropy of magnetic remanence methods-A user's guide for application to paleomagnetism and magnetic fabric studies. In Magnetic Fabrics: Methods and Applications; Martín-Hernández, F., Lüneburg, C.M., Aubourg, C., Jackson, M., Eds.; The Geological Society: London, UK, 2004; Volume 238, pp. 21-35.

112. Fleet, M.E. Micas, 2nd ed.; The Geological Society: London, UK, 2003; 758p.

113. Deer, W.A.; Howie, R.A.; Zussman, J. Layered Silicates Excluding Micas and Clay Minerals, 2nd ed.; The Geological Society: London, UK, 2009; Volume 3B.

114. Deer, W.A.; Howie, R.A.; Zussman, J. Orthosilicates, 2nd ed.; The Geological Society: London, UK, 1997; 919p.

115. Haerinck, T.; Debacker, T.N.; Sintubin, M. Magnetic anisotropy in chloritoid. J. Geophys. Res. Solid Earth 2013, 118, 3886-3898. [CrossRef]

116. Ballet, O.; Fuess, H.; Fritzsche, T. Magnetic structure and cation distribution in $(\mathrm{Fe}, \mathrm{Mn})_{2} \mathrm{SiO}_{4}$ (olivine) by neutron diffraction. Phys. Chem. Miner. 1987, 15, 54-58. [CrossRef]

117. Ferré, E.C.; Tikoff, B.; Jackson, M. Corrigendum to "the magnetic anisotropy of mantle peridotites: Example from the Twin Sisters dunite, Washington" [tectonophysics 398 (2005) 141-166]. Tectonophysics 2005, 405, 233. [CrossRef]

118. Deer, W.A.; Howie, R.A.; Zussman, J. Single-Chain Silicates; Longman Group Ltd.: London, UK, 1978; Volume 2A, 668p.

119. Deer, W.A.; Howie, R.A.; Zussman, J. Double-Chain Silicates, 2nd ed.; The Geological Society: London, UK, 1997; 764p.

120. Povarennykh, A.S. On the magnetic properties of minerals. In Aspects of Theoretical Mineralogy in the U.S.S.R.-A Collection of Papers; Battey, M.H., Tomkeieff, S.I., Eds.; Pergamon Press: Oxford, UK, 1964.

121. Biedermann, A.R.; Pettke, T.; Angel, R.J.; Hirt, A.M. Anisotropy of magnetic susceptibility in alkali feldspar and plagioclase. Geophys. J. Int. 2016, 205, 479-489. [CrossRef]

122. Rochette, P. Inverse magnetic fabric in carbonate-bearing rocks. Earth Planet. Sci. Lett. 1988, 90, $229-237$. [CrossRef]

123. Foex, M.G. Recherches sur le paramagnétisme. Ann. Physiq. 1921, 16, 174-305. [CrossRef]

124. Krishnan, K.S.; Banerjee, S. Magnetic studies on rhodochrosite, $\mathrm{MnCO}_{3}$. Z. Krist. 1938, 99, 499-508. [CrossRef]

125. Rochette, P.; Aubourg, C.; Perrin, M. Is this magnetic fabric normal? A review and case studies in volcanic formations. Tectonophysics 1999, 307, 219-234. [CrossRef]

126. De Wall, H. The field dependence of ac susceptibility in titanomagnetites: Implications for the anisotropy of magnetic susceptibility. Geophys. Res. Lett. 2000, 27, 2409-2411. [CrossRef]

127. Jackson, M.; Moskowitz, B.; Rosenbaum, J.; Kissel, C. Field-dependence of ac susceptibility in titanomagnetites. Earth Planet. Sci. Lett. 1998, 157, 129-139. [CrossRef]

128. Fuller, M.D. Magnetic anisotropy and paleomagnetism. J. Geophys. Res. 1963, 68, 293-309. [CrossRef] 
129. Robinson, P.; Heidelbach, F.; Hirt, A.M.; McEnroe, S.A.; Brown, L.L. Crystallographic-magnetic correlations in single-crystal haemo-ilmenite: New evidence for lamellar magnetism. Geophys. J. Int. 2006, 165, 17-31. [CrossRef]

130. Hrouda, F.; Siemes, H.; Herres, N.; Hennig-Michaeli, C. The relationship between the magnetic anisotropy and the c-axis fabric in a massive hematite ore. J. Geophys. 1985, 56, 174-182.

131. Flanders, P.J.; Schuele, W.J. Anisotropy in the basal plane of hematite single crystals. Philos. Mag. 1964, 9, 485-490. [CrossRef]

132. Worm, H.-U. Magnetic stability of oceanic gabbros from ODP hole 735B. Earth Planet. Sci. Lett. 2001, 193, 287-302. [CrossRef]

133. Mainprice, D.; Humbert, M. Methods of calculating petrophysical properties from lattice preferred orientation data. Surv. Geophys. 1994, 15, 575-592. [CrossRef]

(c) 2018 by the author. Licensee MDPI, Basel, Switzerland. This article is an open access article distributed under the terms and conditions of the Creative Commons Attribution (CC BY) license (http://creativecommons.org/licenses/by/4.0/). 